
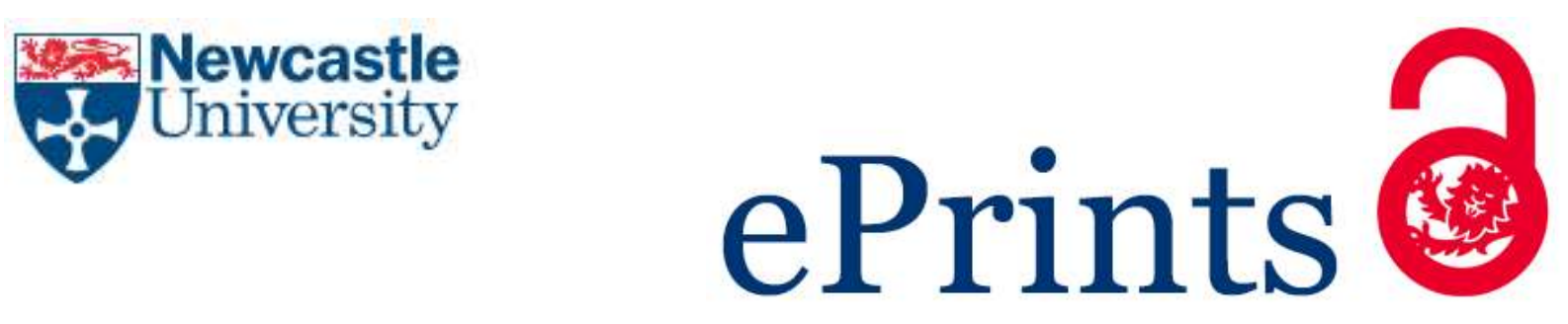

Jacobi V, Schwarze J, Finlay JA, Nolte KA, Spöllman S, Becker H-W, Clare AS,

Rosenhahn A. Amphiphilic alginates for marine antifouling applications. Biomacromolecules 2018

\title{
Copyright:
}

This document is the Accepted Manuscript version of a Published Work that appeared in final form in Biomacromolecules. (C) American Chemical Society after peer review and technical editing by the publisher.

DOI link to article:

https://doi.org/10.1021/acs.biomac.7b01498

Date deposited:

$09 / 01 / 2018$

Embargo release date:

21 December 2018

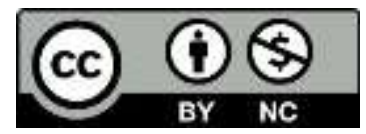

This work is licensed under a Creative Commons Attribution-NonCommercial 3.0 Unported License 


\section{Amphiphilic alginates for marine antifouling}

\section{2 applications}

3 Victoria Jakobi ${ }^{1}$, Jana Schwarze ${ }^{1}$, John A. Finlay', Kim A. Nolte ${ }^{1}$, Stephan Spöllmann ${ }^{3}$, Hans-

4 Werner Becker ${ }^{3}$, Anthony S. Clare ${ }^{2}$, Axel Rosenhahn ${ }^{1 *}$

$5 \quad{ }^{1}$ Analytical Chemistry - Biointerfaces, Ruhr-University Bochum, 44780 Bochum, Germany.

$6 \quad{ }^{2}$ School of Natural and Environmental Sciences, Newcastle University, Newcastle upon Tyne

7 NE1 7RU, UK.

$8 \quad{ }^{3}$ RUBION, Central unit for ion beams and radionuclides, University of Bochum, 44780

9 Bochum, Germany.

10 Keywords: Marine antifouling, fouling-release, coatings, amphiphilic, polysaccharide,

11 alginate, Navicula perminuta, Ulva linza, protein resistance.

12 Abstract

13 Amphiphilic polymers are promising candidates for novel fouling release coatings for marine 14 applications. We grafted amphiphilic alginates with fluorinated side chains to glass and silicon 15 substrates and characterized the obtained films by contact angle goniometry, spectroscopic 16 ellipsometry, XPS, and ATR-FTIR. The potential to inhibit protein attachment was tested 17 against four different proteins and intermediate fluorine loadings showed the strongest 18 reduction with respect to hydrophobic, aliphatic controls. A similar trend was observed in dynamic attachment experiments using Navicula perminuta diatoms and settlement experiment 
with zoospores of the green algae Ulva linza. The results indicate that amphiphilic alginates are promising natural and renewable biomacromolecules that could be included in future protective coating technologies.

\section{Introduction}

Silicone paints are frequently applied to vessels as non-toxic marine protective coatings. They facilitate an easy removal of fouling organisms (fouling-release, FR) so that fast moving ships are capable to self-clean ${ }^{1}$. Recently, coating research started to increasingly explore amphiphilic polymers $^{2-4}$. In this class of polymers, hydrophobic and hydrophilic chains are arranged in close vicinity. While the exact mechanism by which such coatings reduce fouling is still under discussion, the presence of hydrophilic groups favors hydration and lowers the shear stress required to remove slimes ${ }^{1,5}$. In particular the ability of an amphiphilic coating to reorganize under water, including segregation effects, seem to be advantageous for their performance. Recent innovations include the incorporation of amphiphilicity to SEBS polymers ${ }^{6}$, the use in PDMS-based polymers $^{7,8}$, incorporation into polyelectrolyte multilayers ${ }^{9}$, and the application of hyperbranched polymers that combine PEG and perfluorinated hydrocarbons ${ }^{10,11}$. In most of the cases, the introduced amphiphilicity enhanced the fouling-release behavior in laboratory or in field studies. Amphiphilic coatings can form nano-domains which are currently hypothesized to contribute to the exceptional fouling-release properties ${ }^{10}$.

Since renewable materials are increasingly considered, polysaccharides offer a promising class of hydrophilic materials as alternatives to PEG. Besides their biocompatibility, they are capable of binding water tightly and bear numerous functional groups with potential for further chemical modification. Most importantly, they occur in nature and are fully biocompatible. Biomedical applications provided early examples of their antifouling capabilities $^{12-14}$. For marine antifouling applications, self-assembled monolayer (SAM)-based 
studies have demonstrated the importance of the structure of oligosaccharides to produce the most effective resistance to fouling organisms ${ }^{15,16}$. The integration of additional hydrophobic or amphiphilic components into the polysaccharide hydrogel has been shown to increase their antifouling performance ${ }^{15,17,18}$. In addition, polysaccharides, such as hyaluronans, chondroitins and alginates, showed promising performance as marine antifouling materials ${ }^{18-20}$. A drawback of such coatings is that the carboxyl groups of the $\alpha$-L-guluronate tend to bind bivalent cations within the polysaccharide matrix ${ }^{19}$, which can be understood on the basis of the "egg box"gelation model ${ }^{21}$. Since this phenomenon results in changes within the film structure and reduces the water binding capability, some of the coatings show a decreased performance ${ }^{19}$. As blocking of the free carboxyl groups inhibits the binding of bivalent cations, different polysaccharides were post-modified with 2,2,2-trifluoroethylamine (TFEA) via EDC/NHS chemistry, which led to average fluorination degrees of $6-8 \%$ of the available carboxyl groups ${ }^{17,18}$. Besides the inhibition of the gelation process, an amphiphilic character was obtained and the water contact angle of the inherently hydrophilic polysaccharides was shifted towards the Berg limit ${ }^{22}$. Such coatings show enhanced antifouling activity compared to the unmodified controls ${ }^{17,18}$. In particular alginates are a very interesting class of biomacromolecules as they occur in the EPS of biofilms ${ }^{23}$ and in the mucilage and cell walls of seaweeds ${ }^{24}$. The industrial alginate production amounts to 40,000 tons per year ${ }^{24}$ and provides a material that is inherently abundant in nature, renewable, biocompatible, and non-toxic.

This work focuses on a hydrophobic capping route for alginates leading to enhanced fluorine loadings. The capping reagent 2,2,3,3,3-pentafluoropropylamine (PFPA) was chosen instead of TFEA in order to obtain a higher fluorine loading after modification. To enhance the coupling efficiency, the coupling step was done in solution prior to the grafting step. Alginic acid (AA) based coatings with different degrees of PFPA modification were prepared, 


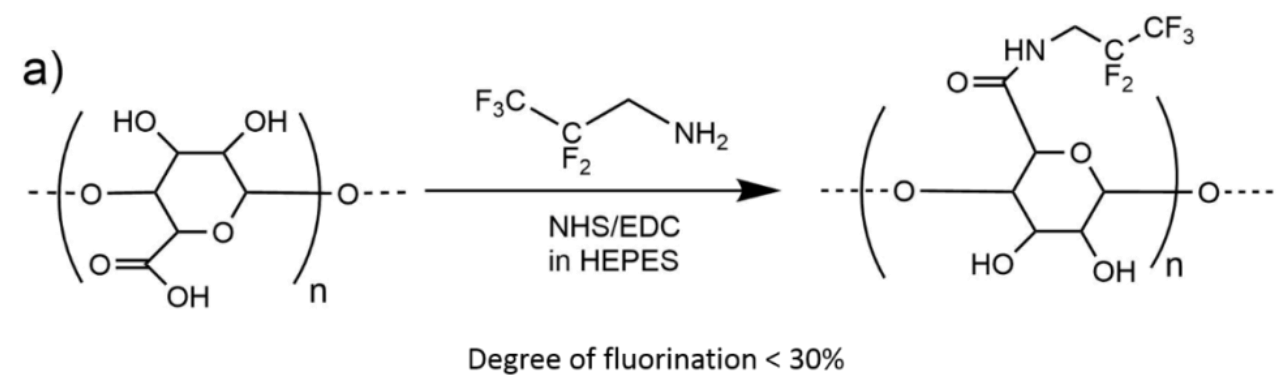

b)

Figure 1 Reaction scheme of polysaccharide modification and the immobilization reaction. a) NHS/EDC-mediated capping of AA-carboxylate groups with PFPA. Stoichiometric ratios of PFPE and the monosaccharide units in the coupling solution was varied between $25 \%$ and $75 \%$ of the functional groups. b) Immobilization reaction of (modified) AA onto an amineterminated silane surface.

PFPA was purchased from Alpha Aesar (Germany). All other chemicals were purchased from Sigma-Aldrich (Germany). All chemicals were used without further purification. Deionized water was purified with a Siemens Water Technologies system. Si wafers (Siegert Wafer, Germany) and Nexterion B float glass slides (Schott, Germany) were used as substrates. 
To functionalize the alginate (molecular weight $100-200 \mathrm{kDa}$, Sigma, Norway \#71238) with PFPA, it was dissolved in 4-(2-hydroxyethyl)-1-piperazineethanesulfonic acid (HEPES) buffer solution (10 mM, pH 6-7) at a concentration of $1 \mathrm{mg} / \mathrm{mL}$ and activated via 1ethyl-3-(3-dimethylaminopropyl)carbodiimide (EDC, 50mM) and N-hydroxysuccinimide (NHS, 10mM) for $15 \mathrm{~min}$. Subsequently, PFPA was added in different stoichiometric quantities $(25 \%, 50 \%, 75 \%)$ to achieve the desired degree of modification of the carboxyl groups. The solution was stirred for $18 \mathrm{~h}$ at room temperature. The amount of PFPA was adjusted to achieve theoretical degrees of modification between $25 \%$ and $75 \%$ of the available carboxylate groups (Figure 1a).

For the surface grafting step, the substrates were first coated with a layer of 3aminopropyltrimethoxy silane (APTMS) following published protocols ${ }^{18,19}$. The surfaces were cleaned in solvents of increasing polarity (toluol, ethyl acetate, ethanol, MilliQ water; 30sec each). The dried samples were activated in an $\mathrm{O}_{2}$ plasma $\left(\mathrm{O}_{2}\right.$ pressure $0,4 \mathrm{mbar}, 80 \mathrm{~W}, 22 \mathrm{kHz}$, miniFlecto-PC-MFC, GaLa Instrumente GmbH, Bad Schwalbach, Germany) and afterwards immersed into a $5 \%(\mathrm{v} / \mathrm{v})$ APTMS solution in acetone and sonicated for 30 min under a nitrogen atmosphere. The surface coupling of the fluorinated AA polymer was performed by a reactivation of the remaining free carboxyl groups with EDC/NHS chemistry. After 15 min of activation, the APTMS-coated substrates were immersed into the polysaccharide solution on a shaker table at room temperature for $18 \mathrm{~h}$. To terminate the reaction, the solution was diluted by an 8 -fold excess of deionized water. The samples were kept on a shaker for another 2 days and the water was exchanged every $24 \mathrm{~h}$. All samples were kept under MilliQ water until characterization and biological evaluation.

\section{Spectroscopic ellipsometry}


All film thicknesses were determined by spectroscopic ellipsometry (M-2000, J. A. Woollam,

107 USA; CompleteEASE software package) operating in a wavelength range of 200-1000 nm at 108 three different angles of incidence $\left(65^{\circ}, 70^{\circ}\right.$, and $\left.75^{\circ}\right)$. The ellipsometry data were modeled as

109 single organic layer on silicon and the wavelength depending refractive index was described by 110 a Cauchy model with the parameters $\mathrm{A}=1.45, \mathrm{~B}=0.01$ and $\mathrm{C}=0$. The presented data are the 111 average of at least three different measurements on at least three different replicates. Error bars 112 represent the standard deviation of the data.

\section{$114 \quad$ Water contact angle goniometry}

115 A custom-built goniometer was used to obtain the static water contact angle (CA). A droplet 116 of MilliQ water was placed on the surface, monitored by a CCD-camera and afterwards 117 analyzed regarding its shape by Young's equation. The data represent the average of three 118 different replicates with three different spots measured on each replicate. Error bars represent 119 the standard deviation.

$121 \quad$ ATR-FTIR

122 A Tensor 27 spectrometer (Bruker, Ettlingen, Germany) with an Ge-ATR cell and a liquid $123 \mathrm{~N}_{2}$-cooled MTC detector was used to obtain the ATR-FTIR spectra. Prior to the measurements, 124 the spectrometer was purged with nitrogen for $30 \mathrm{~min}$. As background the spectrum of the Ge125 ATR crystal was used.

\section{X-ray photoelectron spectroscopy}

128 To determine the derivatization efficiency of the polysaccharide films, X-ray photoelectron 129 spectroscopy (XPS) was applied (electron spectrometer with a hemispheric analyzer Type 130 CLAM2, VG Scientific, meanwhile Thermo Fischer Scientific, Waltham, Massachusetts, 
131 USA). As X-ray source, a polychromatic aluminum anode $\left(\mathrm{K}_{\alpha}=1486 \mathrm{eV}\right)$ was used. The

132 spectra were calibrated on the Si2p substrate signal at $103.4 \mathrm{eV}$ and fitted with OriginPro2017G

133 by applying a background subtraction according to Shirley ${ }^{25}$ and a Voigt profile with a Lorentz

134 to Gauß ratio of 4:1. To determine the elemental ratios between carbon (carbonic acid and amide

135 contribution at $288 \mathrm{eV})$ and fluorine $(689 \mathrm{eV})$, cross sections $\left(\sigma_{\mathrm{C} 1 \mathrm{~s}}=1.0, \sigma_{\mathrm{F} 1 \mathrm{~s}}=4.43\right)$ from

136 Scofield were used ${ }^{26}$.

137

$138 \quad$ Coating stability test

139 The samples were immersed into salt water mixed together from the seven major ingredients 140 of sea water $^{27}$ and filtered through a $0.45 \mu \mathrm{m}$ syringe filter for the desired time period.

141 Afterwards, the surfaces were rinsed with MilliQ water to remove adsorbed salts and dried in a

142 stream of nitrogen. The film thickness was determined by spectroscopic ellipsometry after each

143 immersion step.

\section{Protein adsorption assay}

146 Table 1 Properties of proteins used for the adsorption experiments.

\begin{tabular}{|l|l|l|l|}
\hline Protein & $\begin{array}{l}\text { Molecular } \\
\text { weight }(\mathrm{kDa})\end{array}$ & $\begin{array}{l}\text { Net charge } \\
\text { at } \mathrm{pH} 7.4\end{array}$ & $\begin{array}{l}\text { Protein } \\
\text { concentration }\end{array}$ \\
\hline Lysozyme & 14.7 & + & $2 \mathrm{mg} / \mathrm{mL}$ \\
\hline $\begin{array}{l}\text { Pyruvate } \\
\text { kinase (PK) }\end{array}$ & 237 & + & $160 \mathrm{units} / \mathrm{mL}$ \\
\hline $\begin{array}{l}\text { Bovine serum } \\
\text { albumin (BSA) }\end{array}$ & 66.5 & - & $2 \mathrm{mg} / \mathrm{mL}$ \\
\hline Fibrinogen & 340 & - & $2 \mathrm{mg} / \mathrm{mL}$ \\
\hline
\end{tabular}

147

148 For the protein adsorption assays, Si wafers were used as substrates to provide the reflectivity

149 needed for the spectroscopic ellipsometry experiments. Various proteins, which differ in 
150 molecular weight and net charge at a $\mathrm{pH}$ of 7.4 (Table 1), were studied regarding their

151 adsorption behavior. The selection of proteins and the procedure of the assay followed

152 previously published protocols ${ }^{28,29}$. The assay in its present form was developed in order to

153 consider a certain range of protein charges and sizes. The attachment of these four proteins has

154 so far been investigated on a large range of surface chemistries and allows now a comparative

155 discussion. For this reason, non-resistant dodecanethiol (DDT purchased from Prochima, Spot,

156 Poland) was assembled as SAM on gold-coated Si wafers and included in the assay as a non-

157 resistant control. After a preincubation step in phosphate-buffered saline (PBS, 0.01M pH, 7.4)

158 for $20 \mathrm{~min}$, an equal volume of protein solution (2 $\mathrm{mg} / \mathrm{mL}$ dissolved in PBS) was added and

159 incubated for an additional $30 \mathrm{~min}$ on a shaking table. Subsequently, the samples were flooded

160 with ample amounts of deionized water and carefully rinsed with MilliQ water when passing

161 through the air/water interface to prevent the deposition of Langmuir films. After drying in a

162 stream of nitrogen, the protein thickness was determined by spectroscopic ellipsometry. The

163 adsorbed protein adlayers were modeled in the same way with the same parameters for the

164 Cauchy model as the grafted polysaccharide films.

165

166

\section{Settlement of zoospores of green algae}

167 Zoospores were released from mature plants of $U$. linza and settled on the test surfaces

168 following previously published protocols ${ }^{30}$. Six replicates of each coating, as well as a

169 hydrophobic $n$-octadecyltrichlorosilane (OTS) control were placed in individual compartments

170 of quadriPERM dishes (Greiner Bio-One, Germany) and incubated in filtered artificial seawater

$171(0.22 \mu \mathrm{m})$ for $1 \mathrm{~h}$ prior the experiment. The OTS controls were chosen due to hydrophobic

172 properties, low protein resistance, and typically high numbers of settled zoospores. After pre-

173 incubation, the seawater was exchanged for a zoospore suspension $\left(10 \mathrm{ml} ; 1 \times 10^{6}\right.$ spores $\left./ \mathrm{mL}\right)$

174 and again incubated for $45 \mathrm{~min}$ in darkness at $20^{\circ} \mathrm{C}$. The slides were washed by passing back 
175 and forth through a beaker of seawater for 10 times. Spores were then fixed in $2.5 \%$

176 glutaraldehyde solution in seawater. Using the autofluorescence of chlorophyll within the

177 spores for visualization, the density of the attached spores was determined. Thirty fields of view

178 (each $0.15 \mathrm{~mm}^{2}$ ) were acquired with fluorescence microscopy on each slide. Significant

179 differences in spore settlement densities were determined using ANOVA and Tukey tests with

180 a confidence value of $\mathrm{p}<0.05$.

181

\section{Microfluidic diatom accumulation assay}

183 Diatom culture and the microfluidic accumulation assay followed previously published

184 protocols $^{31}$. The diatom Navicula perminuta was used as a model organism. For the assay, the 185 culture medium was exchanged for filtered seawater (FSW pH 8) and a total cell concentration 186 of 2 million/mL was adjusted using OD 444 . The microfluidic experiment was performed on coated Nexterion B glass slides with OTS as non-resistant control. IBIDI sticky slides 0.1 (IBIDI, Germany) were glued onto the samples and formed the channel system. For each coating, three accumulation assays were conducted at a constant wall shear stress of $0.18 \mathrm{~Pa}$ over $90 \mathrm{~min}$. To remove any unattached diatoms, pure FSW was rinsed through the channels at

191 the same speed as for the accumulation assay. Thirty fields of view $\left(0.5478 \mathrm{~mm}^{2} ; 830 \mu \mathrm{m} \mathrm{x}\right.$ $665 \mu \mathrm{m})$ in the middle of the channel were recorded with an inverted video microscope (Nikon Ti-E, Nikon Japan; 10-x phase contrast objective Nikon CFI Plan Fluor DLL NA 0.3, Nikon

194 Japan). To account for slight variations in the physiological state of the diatoms, OTS was

195 included as non-resistant control and the data obtained were normalized to the attachment on

196 OTS (absolute diatom densities on OTS varied between $237 \mathrm{~mm}^{-2}$ and $542 \mathrm{~mm}^{-2}$ ). The result 197 presented is the average of three independent assays. Statistical analysis was carried out in the same as for the Ulva zoospore assay. 
Table 2 Coating chemistries analyzed in this work include the unmodified alginates (AA) and 203 three PFPA modified ones (AA25PF, AA50PF, and AA75PF). The stoichiometric PFPA content in solution for the coupling step was chosen between $25 \%$ and $75 \%$ with respect to the available carboxylate groups. This resulted in a modification degree of the carboxylate groups which was determined by XPS (third column). The obtained film thickness and its wettability was determined by spectroscopic ellipsometry and water contact angle goniometry.

\begin{tabular}{|l|l|l|l|l|}
\hline Chemistry & $\begin{array}{l}\text { Stoichiometric } \\
\text { PFPA content }\end{array}$ & $\begin{array}{l}\text { Modification } \\
\text { degree }\end{array}$ & $\begin{array}{l}\text { Contact } \\
\text { angle }\left({ }^{\circ}\right)\end{array}$ & $\begin{array}{l}\text { Ellipsometric } \\
\text { thickness (nm) }\end{array}$ \\
\hline AA & $0 \%$ & $0 \%$ & $17 \pm 3$ & $1.7 \pm 0.3$ \\
\hline AA25PF & $25 \%$ & $9 \%$ & $28 \pm 4$ & $2.4 \pm 0.4$ \\
\hline AA50PF & $50 \%$ & $18 \%$ & $34 \pm 3$ & $2.5 \pm 0.4$ \\
\hline AA75PF & $75 \%$ & $28 \%$ & $47 \pm 3$ & $2.8 \pm 0.5$ \\
\hline
\end{tabular}

The impact of the degree of capping of carboxylate groups in the AA polymer on the thickness of the grafted macromolecules and on their wettability was determined. The coupling was carried out in solution by pre-activating the AA by EDC/NHS and subsequently adding the 212 PFPA. The molar ratio of the PFPA in the coupling solution with respect to the monosaccharide 213 units in AA varied between $25 \%$ and $75 \%$ of the available carboxylate groups. Both, the 214 unmodified AA as well as PFPA-modified AA were grafted onto an aminosilane functionalized 215 surface after reactivation of the remaining carboxyl groups by EDC/NHS. The unmodified AA 216 coatings showed a thickness of $1.7 \mathrm{~nm} \pm 0.3 \mathrm{~nm}$ and hydrophilic properties with a CAs of $21717^{\circ} \pm 3^{\circ}$. Introduction of fluorinated compounds increased the thickness of the coatings with 218 variations within the error bars of the measurements between $2.4 \mathrm{~nm}$ and $2.8 \mathrm{~nm}$ (Table 2). 219 Decisive differences were observed for the wettability of the different coatings. An increasing 
220 load of fluorine-rich moieties increased the water contact angles. Coatings with the highest

221 fluorine load reached a water contact angle of $47^{\circ} \pm 3^{\circ}$, which is an increase of $30^{\circ}$ compared 222 to the pristine AA (Table 2).

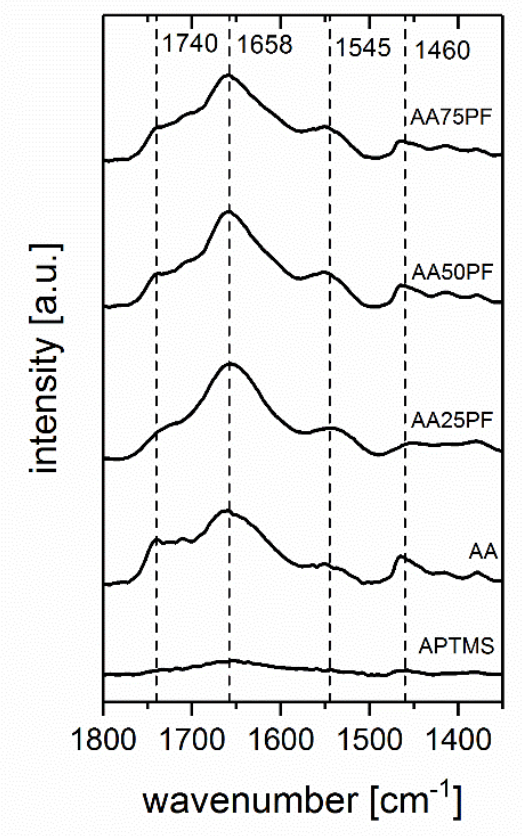

224 Figure 2 ATR-FTIR spectra of an APTMS film, an unmodified AA coating and three modified 225 AA films with increasing amount of PFPA. The intensity of the spectra are normalized to the Si-O vibration at $1230 \mathrm{~cm}^{-1}$.

In order to prove the PFPE modification and the successful grafting to the substrates, ATRFTIR spectra were recorded. As shown in Figure 2, all coatings showed a distinct vibration mode at $1658 \mathrm{~cm}^{-1}$ that can be assigned to the deformation vibration of the terminal $\mathrm{NH}_{2}$ groups. ${ }^{32,33}$ After grafting of AA to the APTMS coated substrates, the vibration at $2311658 \mathrm{~cm}^{-1}$ is strongly enhanced and originates from the $\mathrm{C}=\mathrm{O}$ stretching vibration dominated by 232 the newly formed amide bound. Additionally, the vibration at $1740 \mathrm{~cm}^{-1}$ can be assigned to the 233 six membered lactone ring of $\mathrm{AA} \cdot{ }^{33}$ In the PFPA modified layers, further amide bonds were 234 formed, so that the amide I band at $1658 \mathrm{~cm}^{-1}$ becomes more intense with increasing amounts 235 of PFPA. The same is true for the less intense amid II band at $1545 \mathrm{~cm}^{-1} .^{32}$ The $1460 \mathrm{~cm}^{-1}$ mode 
can be found in all spectra and might originate from the $\mathrm{CH}_{2}$ bending vibration from the

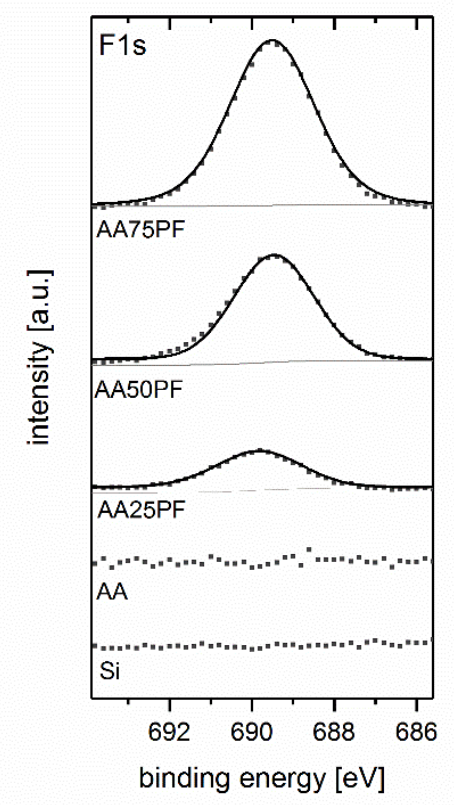

240 Figure $3 \mathrm{~F} 1 \mathrm{~s}$ photoelectron spectra of a plasma-treated silicon wafer, an unmodified AA film 241 and three modified AA films with increasing PFPA content.

242 Additionally to the IR spectroscopy, XPS was used to chemically characterize the modified 243 AA coatings. The successful coupling of PFPA was monitored using the F1s signal at $689 \mathrm{eV}$, 244 which increased with increasing solution concentration of PFPA during the coupling reaction 245 (Figure 3). To determine the fraction of PFPA modified carboxyl groups, the ratio between the 246 F1s signal at $689 \mathrm{eV}$ (Figure 3) and the carbonyl contribution to the $\mathrm{C} 1 \mathrm{~s}$ signal at $288 \mathrm{eV}$ (supplementary figure 1) were calculated considering of the respective elemental cross sections by Scofield ${ }^{26}$. The fluorination reaction resulted in $9.3 \%, 18.3 \%$ and $28.3 \%$ of PFPA modified carboxylic acid groups. Since the derivatization was performed prior to the grafting step, a 250 uniform derivatization throughout the polysaccharide macromolecules can be assumed. 


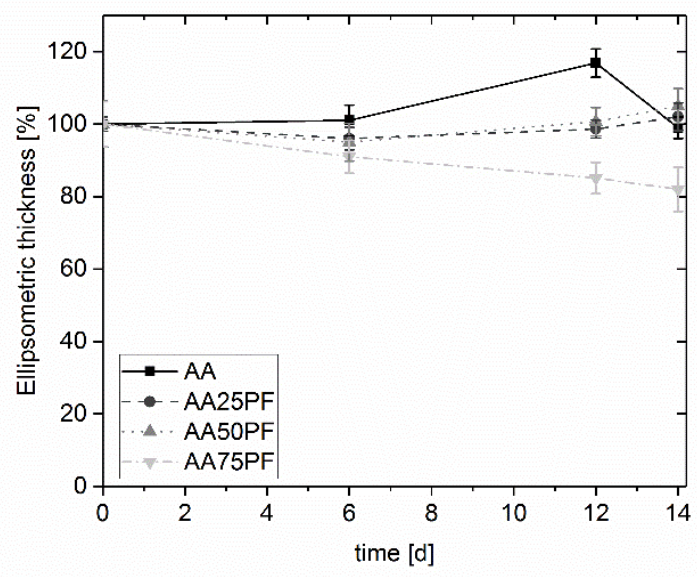

254 Figure 4 Relative thickness change of polysaccharide coatings with different degree of PFPA 255 modification after incubation in salt water. Thicknesses were determined by spectroscopic 256 ellipsometry. Error bars represent the standard deviation $(n=9)$.

257 To investigate the coating stability in media with high salinity, the surfaces were incubated 258 in seawater for 14 days. The thickness change was measured by spectroscopic ellipsometry 259 after different immersion times. Figure 4 shows that the overall thickness change for all four 260 coatings varied by less than $20 \%$ over the course of the two weeks. The unmodified AA coating 261 was the most stable one since it lost only $\approx 1 \%$ of its thickness during the incubation. The 262 PFPA-modified coatings lost slightly more material, with the AA75PF coating losing the most 263 (20\%). The stability in MilliQ water (data not shown here) was higher and variations for all 264 coatings were less than $17 \%$. Over the short-term experiments of $90 \mathrm{~min}$ for the diatom 265 accumulation and 45 min for the spore settlement, we are confident that all coatings were stable. 


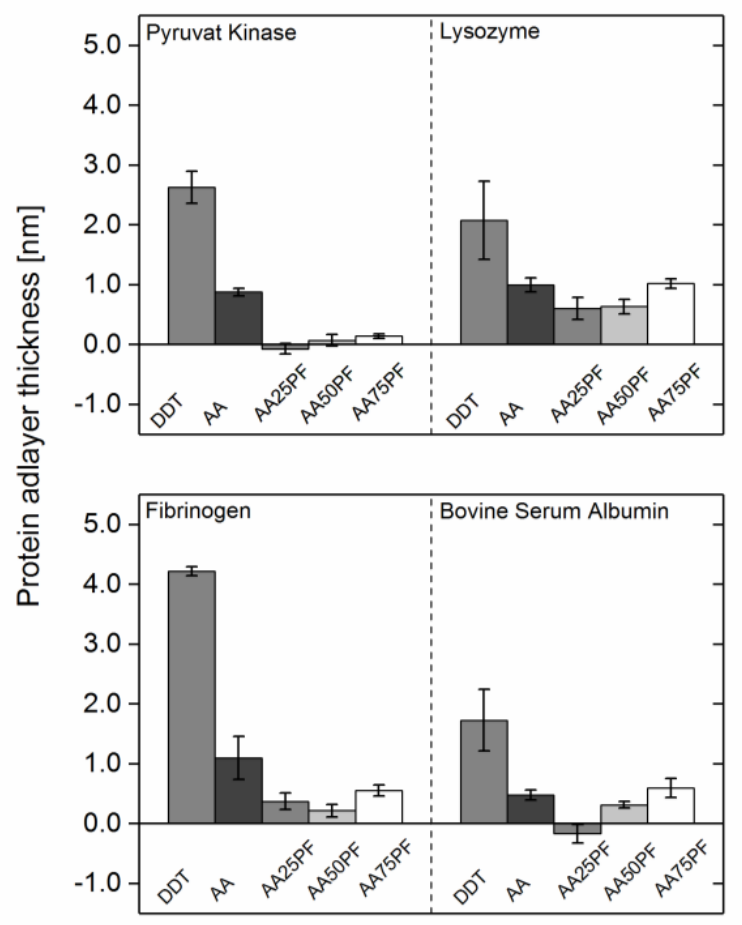

269 Figure 5 Protein adsorption on polysaccharide coatings with different degree of PFPA modification. Adlayer thicknesses were determined by spectroscopic ellipsometry. Error bars 271 represent the standard deviation.

272 The surfaces were tested against the adsorption of different proteins, which varied in size and 273 net charge at a $\mathrm{pH}$ of 7.4 (see Table 1). Figure 5 shows that all of the coatings reduced the 274 adsorption of the proteins with respect to the DDT control significantly $(p<0.05)$. Most of the 275 fluorinated coatings reduced the adsorption to values below the ones found on the unmodified 276 AA coating. This was particularly pronounced for the adsorption of pyruvate kinase and 277 fibrinogen, which was significantly lower $(\mathrm{p}<0.05)$ on the PFPA-modified surfaces compared 278 to AA. Comparing all PFPA-containing surfaces, a low to medium degree of modification led 279 to the most efficient reduction of protein adsorption. For the highest degrees of fluorination, the 280 protein adsorption was found to increase. In the case of lysozyme, the protein film thickness 281 became even higher than on the pristine AA coating. 


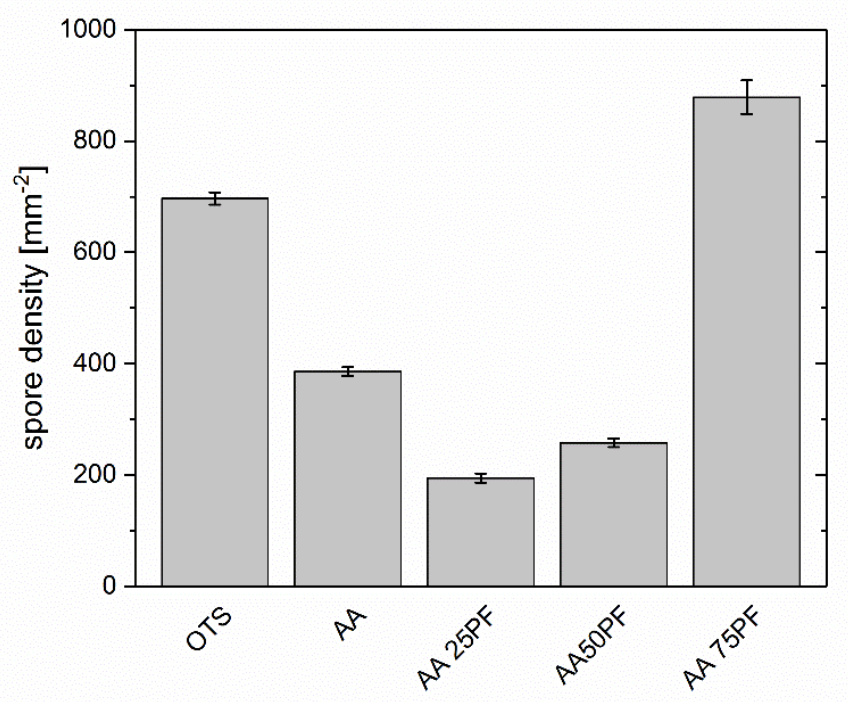

285 Figure $6 \mathrm{U}$. linza spore density after the $45 \mathrm{~min}$ settlement assay. Each point is the average of 286180 counts on six replicate slides. Error bars represent the 95\% confidence limits.

287 Spores of the green algae U. linza are able to explore and select surfaces suitable for 288 settlement ${ }^{34,35}$. Figure 6 shows the density of zoospores on the polysaccharide coatings after the 289 45-min settlement assay. Spore numbers were significantly $(\mathrm{p}<0.05)$ reduced on the AA, 290 AA25PF, and AA50PF coatings with respect to OTS. On the AA75PF coatings that contained 291 the highest PFPA content, spore density was significantly $(\mathrm{p}<0.05)$ enhanced when compared 292 to the hydrophobic control (Figure 6). The lowest spore density was observed at the lowest 293 degree of PFPA capping (AA25PF). The result compares well with the protein adsorption data, 294 in which a low to medium degree of PFPA modification showed the greatest inhibition of 295 protein attachment. 


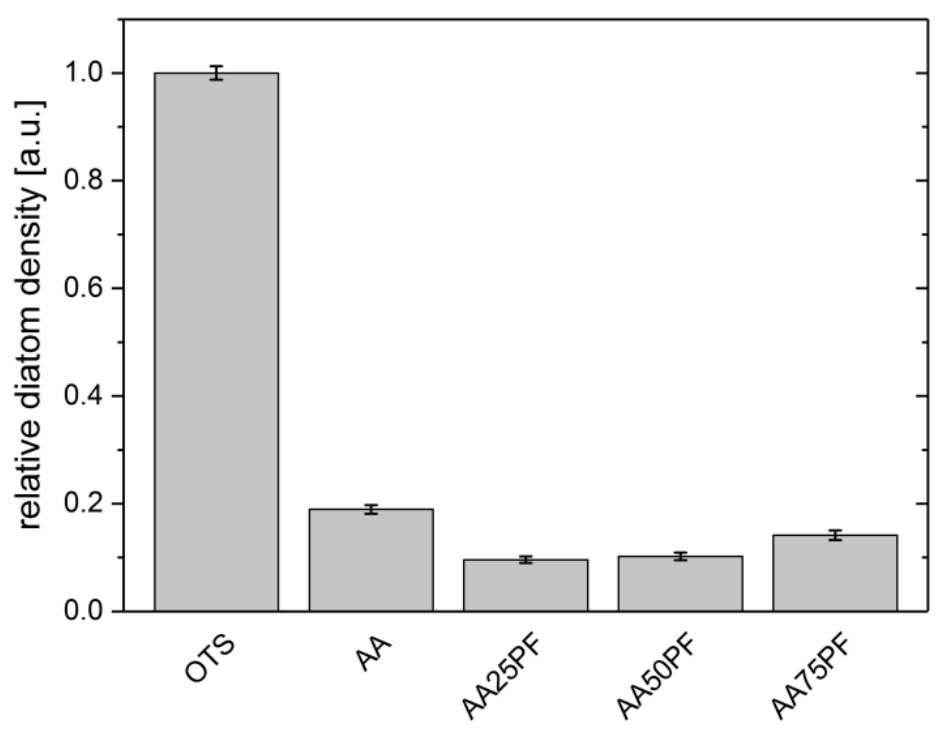

299 Figure 7 Diatom density relative to the non-resistant OTS control after the dynamic attachment experiment. The dynamic assay was performed at $0.18 \mathrm{~Pa}$ for $90 \mathrm{~min}$. OTS was included as non-resistant control. Data represent the average of 30 fields of view on three replicates per chemistry. Error bars are the standard error.

In contrast to zoospores, diatoms like $N$. perminuta are non-motile in the water column and

304 rely on currents and gravity to reach a surface ${ }^{36,37}$. A microfluidic diatom test was used to probe 305 the initial attachment of diatoms to the surface ${ }^{31}$. As previously reported, the initial contact of 306 the diatoms is challenged by the presence of a $0.18 \mathrm{~Pa}$ wall shear stress which makes the assay 307 perceptive for differences in initial attachment strength ${ }^{31}$. For all surfaces, a significant 308 reduction in diatom accumulation was observed as compared to the non-resistant OTS control $309(\mathrm{p}<0.05)$. Significant differences in diatom attachment were identified between the AA- and 310 PFPA-modified surfaces $(\mathrm{p}<0.05)$. Within the fluorinated set, significant differences were 311 observed between AA75PF and AA25PF as well as between AA75PF and AA50PF. The 312 AA25PF and AA50PF modifications were not significantly different. In line with the zoospore 
settlement assay, the highest reduction in attachment was found for the intermediate degrees of

314 PFPA modification (AA25PF and AA50PF).

\section{Discussion}

A range of PFPA modified AA coatings was prepared and characterized. The efficiency of

318 the modification was determined by XPS and three different PFPA molar ratios were added for

319 the derivatization reaction that resulted in $9 \%, 18 \%$ and $28 \%$ functionalization of the carboxylic

320 acid groups. This exceeds the capping efficiency from previous studies which was up to $8 \%{ }^{17,18}$.

321 In addition, the fluorine content per capping group was increased by $\approx 70 \%$ as PFPA was used

322 instead of TFEA. Thus, the maximum fluorine content of the amphiphilic polysaccharide films

323 was increased by $\approx 500 \%$ as compared to our previous work ${ }^{17,18}$.

324 While the grafting density was barely influenced by the derivatization, a shift (by up to $30^{\circ}$ )

325 towards larger water contact angles was observed with increasing PFPA loading. As the

326 thickness of the grafted polysaccharide coatings did not change for the different degrees of

327 functionalization, sufficiently free carboxylic acid groups were available for the grafting

328 reaction. With contact angles of up to $47^{\circ}$, a wettability slightly below the Berg limit of $65^{\circ} 22,38$

329 was achieved. Previous experiments with ethylene glycols with different chemical termination

330 showed a high resistance to proteins and marine fouling organisms in this wettability range ${ }^{39}$.

331 All coatings were able to reduce the adsorption of the four selected model proteins compared

332 to the hydrophobic DDT control surfaces. This result is in good agreement with previous protein

333 adsorption experiments that used a post-grafting modification approach. The results show that

334 low protein adsorption occurred for the intermediate loadings with $9 \%$ and $18 \%$ capping

335 efficiency. At the highest loadings, and therefore the most hydrophobic surfaces, we found an

336 adverse effect and an increase in the amount of adsorbed protein. It is well known from literature

337 that fluorinated surfaces readily facilitate protein adsorption ${ }^{40}$, surface conditioning ${ }^{29}$, and 
attachment of diatoms ${ }^{41}$ as they facilitate hydrophobic van-der Waals interactions. A balanced amphiphilicity with limited possibilities for hydrophobic interactions seems to be the ideally

340 suited for optimized resistance. Also for the attachment of marine fouling organisms, the 341 intermediate PFPA loadings reduced the attachment density of zoospores of Ulva linza and cells 342 of the diatom Navicula perminuta to very low values. The observed reduction supports literature 343 reports in which the amphiphilic concept has proven to be an effective way to enhance the 344 fouling-release properties of surfaces ${ }^{4}$. The range of hydrophilic materials in such technologies 345 can clearly be extended towards further hydrophilic biomacromolecules in particular from 346 renewable sources.

\section{Conclusion}

Using a derivatization of hydrophilic alginates with fluorinated substituents provides a route to amphiphilic polysaccharides that show promising antifouling properties. Compared to recent publications we increased the fluorine loading per capping molecule and enhanced the capping efficiency for optimized amphiphilicity. Indeed, an optimized fluorine loading was detected that minimized attachment strength of diatoms and settlement of zoospores of the green algae Ulva linza. The data suggests that amphiphilic polysaccharides could be useful building blocks for modern fouling-release coatings as a natural, renewable biomaterial of maritime origin with excellent biocompatibility. It can be expected that such materials find their application in the next generation of environmentally benign coating technologies.

60 List of Supporting Information

61 XPS C1s spectra for AA, AA25PF, AA50PF and AA75PF 
363 * Axel Rosenhahn, Analytical Chemistry - Biointerfaces, Ruhr-University Bochum, 44780

364 Bochum, Germany.

\section{Funding Sources}

367 The work was funded by the Office of Naval Research projects N00014-15-12324 and N0001416-12979 (AR) and N00014-13-1-0633, N00014-13-1-0634, N00014-16-1-2988 and N0001416-1-3125 (A.S.C.), and the cluster of excellence RESOLV (EXC 1069).

(1) Callow, J. A.; Callow, M. E. Trends in the development of environmentally friendly fouling-resistant marine coatings. Nature communications 2011, 2, 244.

374 (2) Krishnan, S.; Weinman, C. J.; Ober, C. K. Advances in polymers for anti-biofouling surfaces. J. Mater. Chem. 2008, 18, 3405.

(3) Hawkins, M. L.; Faÿ, F.; Réhel, K.; Linossier, I.; Grunlan, M. A. Bacteria and diatom resistance of silicones modified with PEO-silane amphiphiles. Biofouling 2014, 30, 247-258.

(4) Galli, G.; Martinelli, E. Amphiphilic Polymer Platforms: Surface Engineering of Films for Marine Antibiofouling. Macromolecular rapid communications 2017, 38, 1600704. 
(7) Martinelli, E.; Suffredini, M.; Galli, G.; Glisenti, A.; Pettitt, M. E.; Callow, M. E.; Callow,

J. A.; Williams, D.; Lyall, G. Amphiphilic block copolymer/poly(dimethylsiloxane) (PDMS)

(8) Martinelli, E.; Sarvothaman, M. K.; Galli, G.; Pettitt, M. E.; Callow, M. E.; Callow, J. A.;

(PDMS) network blends of amphiphilic acrylic copolymers with poly(ethylene glycol)trials. Biofouling 2012, 28, 571-582.

(9) Zhu, X.; Guo, S.; Jańczewski, D.; Velandia, F. J. P.; Teo, S. L.-M.; Vancso, G. J.

Multilayers of fluorinated amphiphilic polyions for marine fouling prevention. Langmuir 2014, 30, 288-296.

(10) Gudipati, C. S.; Greenlief, C. M.; Johnson, J. A.; Prayongpan, P.; Wooley, K. L. Hyperbranched fluoropolymer and linear poly(ethylene glycol) based amphiphilic crosslinked 398 networks as efficient antifouling coatings: An insight into the surface compositions, topographies, and morphologies. J. Polym. Sci. A Polym. Chem. 2004, 42, 6193-6208. Antifouling and Fouling-Release Perfomance of Hyperbranched Fluoropolymer (HBFP) -: Poly(ethylene glycol) (PEG) Composite Coatings Evaluated by Adsorption of

403 Biomacromolecules and the Green Fouling Alga Ulva. Langmuir 2005, 21, 3044-3053.

(12) Morra, M.; Cassineli, C. Non-fouling properties of polysaccharide-coated surfaces. Journal of Biomaterials Science, Polymer Edition 1999, 10, 1107-1124. surfaces. Langmuir 2006, 22, 8192-8196. 
(14) Ombelli, M.; Costello, L.; Postle, C.; Anantharaman, V.; Meng, Q. C.; Composto, R. J.;

409 Eckmann, D. M. Competitive protein adsorption on polysaccharide and hyaluronate modified surfaces. Biofouling 2011, 27, 505-518.

(15) Fyrner, T.; Lee, H.-H.; Mangone, A.; Ekblad, T.; Pettitt, M. E.; Callow, M. E.; Callow,

J. A.; Conlan, S. L.; Mutton, R.; Clare, A. S.; Konradsson, P.; Liedberg, B.; Ederth, T.

Saccharide-functionalized alkanethiols for fouling-resistant self-assembled monolayers:

Ederth, T. Antifouling properties of oligo(lactose)-based self-assembled monolayers. Biofouling 2015, 31, 123-134.

(17) Bauer, S.; Arpa-Sancet, M. P.; Finlay, J. A.; Callow, M. E.; Callow, J. A.; Rosenhahn,

A. Adhesion of marine fouling organisms on hydrophilic and amphiphilic polysaccharides. Langmuir 2013, 29, 4039-4047.

(18) Bauer, S.; Alles, M.; Arpa-Sancet, M. P.; Ralston, E.; Swain, G. W.; Aldred, N.; Clare, Polysaccharides against Marine Fouling Organisms. Biomacromolecules 2016, 17, 897-904.

Callow, M. E.; Grunze, M.; Rosenhahn, A. Resistance of polysaccharide coatings to proteins, hematopoietic cells, and marine organisms. Biomacromolecules 2009, 10, 907-915. biomaterials science. Polymer edition 2014, 25, 1530-1539. 
431 between polysaccharides and divalent cations: The egg-box model. FEBS Letters 1973, 32, $432 \quad 195-198$.

(22) Berg, J. M.; Eriksson, L. G. T.; Claesson, P. M.; Borve, K. G. N. Three-Component 434 Langmuir-Blodgett Films with a Controllable Degree of Polarity. Langmuir 1994, 10, 12254351234

436 (23) Flemming, H.-C.; Neu, T. R.; Wozniak, D. J. The EPS matrix: The "house of biofilm 437 cells". Journal of bacteriology 2007, 189, 7945-7947.

438 (24) Fenoradosoa, T. A.; Ali, G.; Delattre, C.; Laroche, C.; Petit, E.; Wadouachi, A.; Michaud, 439 P. Extraction and characterization of an alginate from the brown seaweed Sargassum 440 turbinarioides Grunow. J Appl Phycol 2010, 22, 131-137.

441 (25) Shirley, D. A. High-Resolution X-Ray Photoemission Spectrum of the Valence Bands 442 of Gold. Phys. Rev. B 1972, 5, 4709-4714.

443 (26) Scofield, J. H. Hartree-slater subshell photoionization cross-sections at 1254 and 444 $1487 \mathrm{eV}$. Journal of electron spectroscopy and related phenomena 1976, 129-137.

(27) Kester, D. R.; Duedall, I. W.; Conners, D. N.; Pytkowicz, R. M. Preparation of artificial 446 seawater. Limnol. Oceanogr. 1967, 12, 176-179.

447 (28) Kevin L. Prime and George M. Whitesides. Adsorption of proteins onto surfaces 448 containing end-attached oligo(ethylene oxide): a model system using self-assembled 449 monolayers. J. Am. Chem. Soc. 1993, 115, 10714-10721.

(29) Thome, I.; Bauer, S.; Vater, S.; Zargiel, K.; Finlay, J. A.; Arpa-Sancet, M. P.; Alles, M.;

451 Callow, J. A.; Callow, M. E.; Swain, G. W.; Grunze, M.; Rosenhahn, A. Conditioning of self- 
452

453

assembled monolayers at two static immersion test sites along the east coast of Florida and its effect on early fouling development. Biofouling 2014, 30, 1011-1021.

(30) Xiao, L.; Thompson, S. E. M.; Röhrig, M.; Callow, M. E.; Callow, J. A.; Grunze, M.; Rosenhahn, A. Hot embossed microtopographic gradients reveal morphological cues that guide the settlement of zoospores. Langmuir 2013, 29, 1093-1099.

(31) Nolte, K. A.; Schwarze, J.; Rosenhahn, A. Microfluidic accumulation assay probes attachment of biofilm forming diatom cells. Biofouling 2017, 33, 531-543.

(32) Hesse, M.; Meier, H.; Zeeh, B. Spektroskopische Methoden in der organischen Chemie: 100 Tabellen, 5., überarb. Aufl.; Thieme: Stuttgart [u.a.], 1995.

(33) Coates, J. Interpratation of Infrared Spectra: A practical Approach. In Encyclopedia of Analytical Chemistry; Meyers, R. A., Ed.; John Wiley \& Sons LTD.: Chichester, 2000; pp $10815-10837$.

(34) Callow, M. E.; Callow, J. A.; Pickett-Heaps, J. D.; Wetherbee, R. Primary adhesion of enteromorpha (chlorophyta, Ulvales) propagules: Quantitative settlement studies and video microscopy. J Phycol 1997, 33, 938-947.

(35) Heydt, M.; Pettitt, M. E.; Cao, X.; Callow, M. E.; Callow, J. A.; Grunze, M.; Rosenhahn, A. Settlement behavior of zoospores of Ulva linza during surface selection studied by digital holographic microscopy. Biointerphases 2012, 7, 33.

(36) Wetherbee, R.; Lind, J. L.; Burke, J.; Quatrano, R. S. The first Kiss: establishment and control of inital adhesion by raphid diatoms. Journal of Pychology 1998, 9-15.

(37) Molino, P. J.; Wetherbee, R. The biology of biofouling diatoms and their role in the development of microbial slimes. Biofouling 2008, 24, 365-379. 
474 (38) Vogler, E. A. Structure and reactivity of water at biomaterial surfaces. Advances in 475 colloid and interface science 1998, 74, 69-117.

476 (39) Schilp, S.; Kueller, A.; Rosenhahn, A.; Grunze, M.; Pettitt, M. E.; Callow, M. E.; Callow, 477 J. A. Settlement and adhesion of algal cells to hexa(ethylene glycol)-containing self-assembled 478 monolayers with systematically changed wetting properties. Biointerphases 2007, 2, 143-150.

479 (40) Ekblad, T.; Andersson, O.; Tai, F.-I.; Ederth, T.; Liedberg, B. Lateral control of protein 480 adsorption on charged polymer gradients. Langmuir 2009, 25, 3755-3762.

481 (41) Alles, M.; Rosenhahn, A. Microfluidic detachment assay to probe the adhesion strength 482 of diatoms. Biofouling 2015, 31, 469-480. 